\title{
Analysis on Chinese Economic Development Under Post-Financial Crisis Environment Based on IS-LM Model
}

\author{
Jiaxuan Wang \\ Department of Mathematics, The University of Manchester, Manchester, M1 2AD, Britain \\ *Corresponding author. Email: gaoming@cas-harbour.org
}

\begin{abstract}
After the subprime mortgage crisis occurred in the United States, the worldwide financial turmoil not only resulted in a series of serious negative consequences in the global financial field, but also brought a relatively big impact for our country's economy. In order to response the global financial crisis, Chinese government has implemented a moderately loose monetary policy of continuous "double rate" reduction since the end of 2008. Based on the IS-LM model, together with the data, about Chinese GDP and Monetary growth rate from 2008 to 2019, collected through the website of Bank of China and other relevant resources, this paper analyzed the effects of the above economic policies. The research result shows that it is very difficult for Chinese market rescue policy to achieve results in the short term, and it is necessary to explicit the direction of investment and the focus of monetary policy in order to promote sustainable and stable economic growth.
\end{abstract}

Keywords: IS-LM model, monetary policy, economic policy, financial crisis

\section{INTRODUCTION}

Since 2007, the turbulence of the sub-prime mortgage market in the United States has triggered a series of events with serious crisis color. The crisis spread the risk through the interconnection between financial markets, and then spread to the global financial system, and finally led to the financial crisis.

With the recession of the world economy and the increasing employment pressure, China has also suffered some losses. Due to the occurrence of the financial crisis, the amount of foreign direct investment in China is also affected by the financial crisis, leading to a decline in corporate performance and a large-scale decline in the stock market. Since then, securities, stock markets, and fund projects, as well as real estate loans, have been deemed untrustworthy by the public, leading to a speculative surplus that has increased to a certain extent in the demand for money and, ultimately, a significant decline in production. Numerically, according to the National Bureau of Statistics, Chinese export growth was only 7 percent in 2008 as a result of the financial crisis, declining 8.5 percent from 2007. What's more, GDP growth slowed to $6.8 \%$ from $12.6 \%$ in 2007 [1]. It can be seen that the financial crisis has a huge impact on China's economy.

In response to this crisis, the Chinese government began to implement the market rescue policy since November 2008, including the continuous substantial "double rate" monetary policy.

This paper first analyzes China's unique IS-LM model and the significance of its various values to China. Then analyzes the actual impact of policy implementation on China and the follow-up direction by combining several groups of figures, in regard to Chinese GDP and Monetary growth rate from 2008 to 2019 collected from an official website called the Bank of China, and the figure established by IS-LM model.

\section{IS-LM MODEL}

IS Curve: $r=\frac{\partial+e}{d}-\frac{1-\beta}{d} y$

LM Curve: $r=\frac{k}{h} y-\frac{m}{h}$ 
"IS-LM" model is an economic analysis model summarized by John Hicks, a famous modern British economist, and John Hanson, the founder of the Keynesian School of the United States, on the basis of Keynes's macroeconomic theory, which is the "Hicks-Hanson Model" [6]. IS-LM model IS an important tool for macroeconomic analysis and is used to describe product markets and the theoretical structure of the interconnection between money and money. Where I stands for investment, $\mathrm{S}$ for savings, $\mathrm{L}$ is the demand for money, and $\mathrm{M}$ is the supply of money.

If the government's macroeconomic policy changes, generally the equilibrium of the IS-LM model will also change. Among them, the change of IS curve is mainly affected by fiscal policy. If the government implements an expansionary fiscal policy, the IS curve moves to the upper right, otherwise, it moves to the lower left. The change of LM curve is mainly affected by the monetary policy. If the government implements the expansionary monetary policy, the LM curve will move to the right and to the lower side; otherwise, it will move to the left and to the upper side.

Within the IS-LM model, the shape of LM curve IS given. Then the steeper IS is, the greater the effect of fiscal policy will be. On the contrary, the flatter the IS curve, the less effective the fiscal policy will be; if the IS curve has a given shape, then the steeper the LM curve, the less effective fiscal policy will be. On the contrary, the flatter the LM curve, the greater the effect of fiscal policy.

\section{THE MODERATELY LOOSE MONETARY POLICY OF "DOUBLE RATE"}

In response to the economic impact of the U.S. financial crisis, the People's Bank of China lowered the benchmark one-year yuan lending rate by 0.27 percentage points to $7.2 \%$ from September 16, 2008. At the same time, starting from September 25, 2008, the deposit financial institutions of the RENMINBI deposit reserve ratio reduced by 1 percentage point [7].

In terms of specific policies, the government clearly has two expectations: one is to lower the lending rate, which is intended to moderately reduce the financing costs of enterprises on the whole and stimulate economic growth; Second, we will lower the reserve requirement ratio for small and medium-sized financial institutions except the five major state-owned banks. The main purpose is to ease the liquidity shortage of small and medium-sized commercial banks and avoid operational risks of financial institutions. At the same time, as small and medium-sized commercial banks are the main source of loans to small and medium-sized enterprises, they can also moderately increase the scale of loans to small and medium-sized enterprises [8].

\section{CHINESE IS-LM MODEL ANALYSIS}

\subsection{For IS Curve}

The marginal propensity to consume is seriously low. China's marginal propensity to consume is about 0.3 , only half the level of countries such as Britain and the United States. This is due to the large proportion of housing and education expenditure in household expenditure and the traditional concept of thrift.

The absolute value of the slope of IS curve $\frac{1-\beta}{d}$ is 1.2 [2], greater than 1, indicating that the IS curve in China IS relatively steep. But with the continuous development of financial markets and the establishment of a sound social security system, this curve will continuously turn to flatten.

\subsection{For LM Curve}

The income elasticity of money demand is high, about 1.2 [2]. This is because the construction of the social security system cannot be completed in a short period of time, as a result Chinese residents' precautionary demand for currency has sharply increased.

The elasticity of money demand rate is relatively low, at about -0.2 [2]. In China, most of the demand for money is for health care, pensions, education and so on. This demand will not be changed by a general change in interest rates. At the same time, the financial market is still imperfect and investment channels are still somewhat lacking.

The LM curve is extremely steep. The absolute slope of China's current LM curve $\mathrm{k} / \mathrm{h}$ is 6 , which is much greater than 1 . However, as equity markets improve and investment options expand, the curve will eventually flatten out.

\section{CHANGE OF CHINESE IS-LM CURVE IN RECENT YEARS}

As a result of the financial crisis in the United States and the policies implemented by the Chinese government, China's economy has undergone great changes. These changes can be clearly shown by IS-LM modeling

\subsection{IS-LM modeling analysis in China}

As mentioned above, both the IS and LM curves of China are steep, while the slope of the LM curve 6 is greater than the IS curve slope 2.2. For a given policy, the steeper the IS curve, the greater the effect; The steeper the LM curve, the less effective the policy will be [4]. Therefore, the IS-LM modeling analysis shows 
that the steep IS curve represents the strong effect of China's current market rescue policies. However the LM curve restricts this effect.

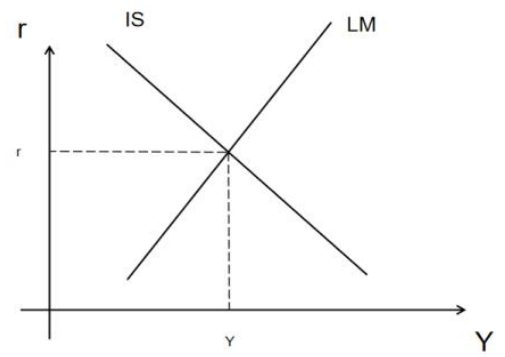

Figure 1 Chinese current IS-LM curve

However, due to the measures taken by the Chinese government in 2008, which invested about 400 billion RMB, local social investment has been greatly stimulated. At the same time, reducing taxes and increasing residents' disposable income also raised the consumption tax level of residents. By definition, governments can increase balanced output while prices remain stable by increasing purchases and reducing taxes. This will be reflected in IS-LM modeling as the IS curve shifts to the right and the equilibrium production $\mathrm{Y}$ increases.

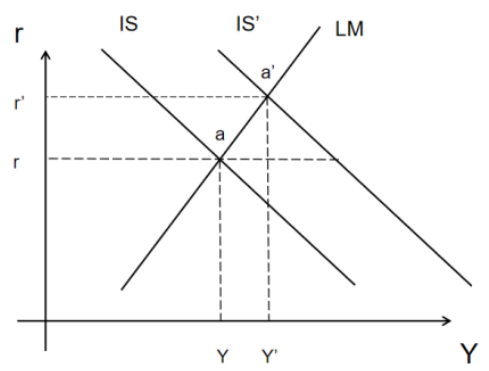

Figure 2 The positive effect of Chinese economic polities

At the same time, relatively loose monetary policy has produced positive gains. According to the foregoing, for a particular monetary policy, the higher the slope of the LM curve, the smaller its effect; The steeper the LM curve, the more effective monetary policy will be [4]. As with economic policy, although the high slope of the LM curve suggests that Chinese monetary policy can achieve good results, the steep IS will also constrain it.

The implementation of moderately loose monetary policy in China is reflected in the government's consecutive substantial double rate reduction. This has allowed commercial banks to lower the cost of funding and increase their enthusiasm for lending. Directly causing the central bank to increase the amount of basic money it issues, increasing the money supply. Later, the Chinese government purchased securities, issued currency, documented monetary base and provided cash in the public market, which also greatly reduced the damage caused by the financial crisis. This series of policies eventually made the currency supply exceed the currency demand, resulting in a decline in interest rates and an increase in investment demand. In IS-LM modeling, the LM curve shifts to the right and the equilibrium interest rate $r$ drops .

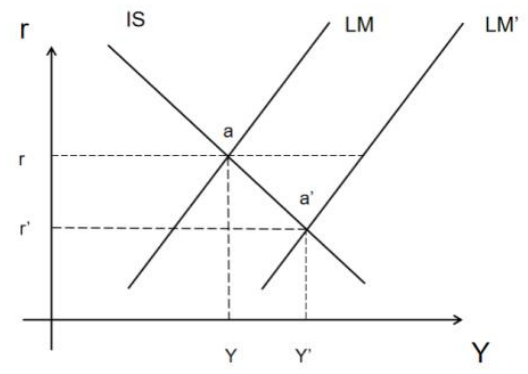

Figure 3 The positive effect of Chinese monetary polities

\subsection{Analysis on the market rescue policies of Chinese government by IS-LM model}

Combined with the IS-LM model, China's IS-LM modeling can be summarized as follows (figure 4):

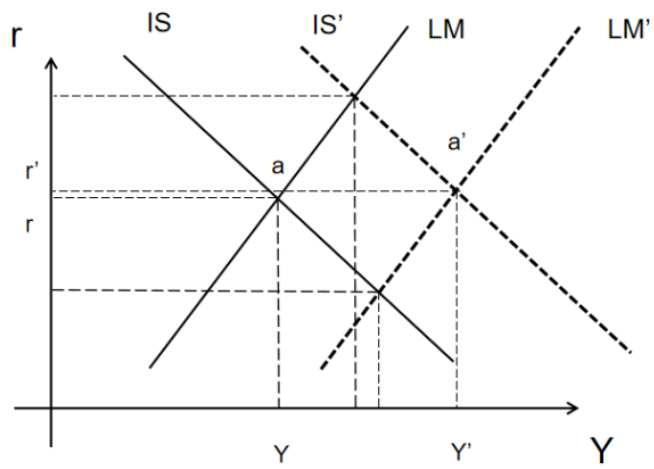

Figure 4 IS-LM model of China

After the huge investment of the Chinese government in the financial market and the implementation of various policies, the IS-LM curve shows that the original equilibrium points a has moved to the right to point a'. This means that the interest rate is essentially the same, but the national income is going from $\mathrm{Y}$ to $\mathrm{Y}^{\prime}$ [5]. This represents an increase in economic growth and GDP, or a reduction in the rate at which the economy is declining 
Table 1. Chinese Monetary growth rate from 2008 to 2015

\begin{tabular}{|c|c|c|c|}
\hline Year & Monetary growth rate (\%) & Year & Monetary growth rate (\%) \\
\hline 2008 & 25.3 & 2012 & 12.3 \\
\hline 2009 & 19.6 & 2013 & 17.6 \\
\hline 2010 & 14.8 & 2014 & 16.9 \\
\hline 2011 & 14,7 & 2015 & 19.6 \\
\hline
\end{tabular}

Data sources: People's Bank of China website (www.pbc.gov.cn)

Table 2. Chinese GDP per capital from 2008 to 2019

\begin{tabular}{|c|c|c|c|}
\hline Year & GDP per capital (RMB) & Year & GDP per capital (RMB) \\
\hline 2008 & 1001.7 & 2014 & 764.0 \\
\hline 2009 & 800.2 & 2015 & 776.4 \\
\hline 2010 & 574.3 & 2016 & 1143.9 \\
\hline 2011 & 375.9 & 2017 & 1793.7 \\
\hline 2012 & 362.5 & 2018 & 1767.8 \\
\hline 2013 & 699.2 & 2019 & 1980.7 \\
\hline
\end{tabular}

Data sources: People's Bank of China website (www.pbc.gov.cn)

It can be concluded from the data in table 1 and table 2, although China's monetary growth rate and per capita GDP declined after 2008, they both began to rise again around 2013. Therefore, it can be seen that the IS-LM modeling analysis is correct. According to the analysis on actual data, the feasibility of IS-LM model is demonstrated.

However, from the reality, the continuous reduction of interest rates in recent years has been very limited to stimulate consumption and investment. This does not suggest a perfect environment for monetary policy to have the most impact. Continuing to implement the same policy has been difficult to achieve the desired effect. Hence the degree of system perfection and the effectiveness of policies should be fully considered when making policy choices. Government spending, in particular, will have an administrative tinge. So perhaps a focus on fiscal policy would do more to help.

\section{CONCLUSION}

Through the analysis on IS-LM modeling, it can be concluded that the moderately loose monetary policy of "double rate" successive reduction has indeed slowed down the harm caused by the financial crisis to China. This can be seen in phenomena such as a large increase in the supply of money in the market. Nevertheless, because the economic effects of various policies are weakened, it cannot have a beneficial impact for a long time. Promoting recovery as a whole may require coordination with other fiscal policies. The establishment of a complete market system will be one of the necessary conditions for China's economic recovery in the post-crisis era.
This paper will consider more realistic macroeconomic factors to improve the IS-LM model in the future. At the same time, combined with other data, the analysis results will be further improved and revised.

\section{REFERENCES}

[1] National Bureau of Statistics of China, www.stats.gov.cn, 2019.

[2] X. Peng. IS-LM model analysis of macro policy under economic crisis, BBS of finance and economic. 2009. 11.

[3] IS-LM Model Analysis of China's Macroeconomic Operation under the Background of Financial Crisis, Douding, 2012. 02.

[4] X. Wang, Y. Wang. An empirical study on the causes and countermeasures of the American financial crisis, Economic observation, 2011. 06.

[5] Y. Zhang. Analysis on the effect of China's monetary policy in coping with the financial crisis, The window of the financial, 2010. 08.

[6] J. Li, W. Chen. IS-LM model and American financial crisis, Managememt World, 2009.11

[7] S. Xu. "Double rate" downward reflects the monetary policy to "maintain growth" titt, China Business Time, 2008/09/16.

[8] F. Zhao. The two rate cut shows a positive signal of monetary policy, Shanghai Securities News, 2008/09/22. 